\title{
Article \\ Different ISO Standards' Wear Kinematic Profiles Change the TKA Inlay Load
}

\author{
Leandra Bauer (D), Manuel Kistler (D), Arnd Steinbrück, Katrin Ingr, Peter E. Müller, Volkmar Jansson, \\ Christian Schröder and Matthias Woiczinski *
}

Department of Orthopedic Surgery, Physical Medicine and Rehabilitation, Campus Grosshadern, University Hospital of Munich (LMU), Marchioninistr. 15, 81377 Munich, Germany; Leandra.bauer@med.uni-muenchen.de (L.B.); manuel.kistler@med.uni-muenchen.de (M.K.); arnd.steinbrueck@med.uni-muenchen.de (A.S.); katrin.ingr@med.uni-muenchen.de (K.I.); peter.mueller@med.uni-muenchen.de (P.E.M.); volkmar.jansson@med.uni-muenchen.de (V.J.); christian.schroeder@med.uni-muenchen.de (C.S.)

* Correspondence: matthias.woiczinski@med.uni-muenchen.de; Tel.: +49-89-4400-74859

check for updates

Citation: Bauer, L.; Kistler, M.; Steinbrück, A.; Ingr, K.; Müller, P.E.; Jansson, V.; Schröder, C.; Woiczinski, M. Different ISO Standards' Wear Kinematic Profiles Change the TKA Inlay Load. Appl. Sci. 2021, 11, 3161 https://doi.org/10.3390/app11073161

Academic Editor: Frank Seehaus

Received: 25 February 2021

Accepted: 29 March 2021

Published: 1 April 2021

Publisher's Note: MDPI stays neutral with regard to jurisdictional claims in published maps and institutional affiliations.

Copyright: (c) 2021 by the authors. Licensee MDPI, Basel, Switzerland. This article is an open access article distributed under the terms and conditions of the Creative Commons Attribution (CC BY) license (https:// creativecommons.org/licenses/by/ $4.0 /)$.

\begin{abstract}
Wear is an important factor in the long-term success of total knee arthroplasty (TKA). Therefore, wear testing methods have become standard in implant research and development. In the EU, these are based on two simulation concepts, which are defined in standards ISO 14243-1 and 14243-3, differentiated by the control mode-force-controlled or displacement-controlled. The aim of this study was to compare the mechanical stresses within the different ISO concepts using a finite element model (the newest displacement-controlled norm from 2014 compared with force-controlled). The in silico model showed strong correlation with the experimental data $(r>0.8)$. The adapted force-controlled ISO showed higher mechanical stress during the gait cycle, which also might lead to higher wear rates (14243-1 (2009): $11.15 \mathrm{MPa}, 10.15 \mathrm{MPa}$ and 9.16 MPa). The displacement-controlled ISO led to higher mechanical stress because of the constraint at the end of the stance phase (14243-3: 20.59 MPa and 17.19 MPa). Future studies should analyse different inlay designs within the same ISO standards to guarantee comparability.
\end{abstract}

Keywords: TKA; wear simulator; ISO standard; FEM; finite element

\section{Introduction}

Total knee arthroplasty (TKA) has been established as an operative procedure for osteoarthrosis with good to very good clinical outcomes and long-term success for patients [1,2]. Nevertheless, in some cases revision surgery is necessary, and in some patients the main reason for implant loosening is osteolysis possibly caused by wear particles $[3,4]$. Therefore, experimental wear testing in a laboratory environment has become an important tool for evaluating new TKA designs and new materials. Furthermore, these tests are also necessary for the approval of newly developed knee implant designs through the notified body. To generate experiments that are comparable across several research groups and companies, standards have been developed.

The International Organization for Standardization (ISO) has two main concepts established: the force-controlled (FC, 14243-1) and displacement-controlled (DC, 14243-3) standards. These standards are reviewed and renewed at regular intervals. The 2002 version was renewed in 2009; the DC norm in 2014. Both standards are used for the wear testing of different TKA designs, with one exception. The displacement-controlled norm states that completely congruent TKA designs may not be tested with this standard. When comparing these two different control modes, they share the same force profile for the axial (femorotibial) compression force and the same flexion/extension profile of the femoral component. The differences are in the control mode of the anterior/posterior translation and internal/external rotation of the tibia component relative to its counterpart, the femoral 
component. The force-controlled norm induces this movement with a load profile on the components, and the displacement-controlled standard therefore uses fixed translational and rotational values. Interestingly, for the displacement standard, the anterior/posterior movement of the tibia and the rotational profile were changed in 2014 to the opposite way around because Sutton et al. showed that the load-controlled standard was not consistent with the displacement-controlled standard in human specimens [5].

Various working groups have been working on similar issues. Mell et al. compared the DC norm of 2004 with the changed one of 2014 [6]. By means of computer simulation, the kinematic inputs, contact condition, and wear of both standards were investigated. They showed a lower wear rate for the newer version, but at the same time a higher wear area. Overall, they were able to show a difference between the two standards and advised that historical wear results be compared with newer results only with caution [6]. In another study, the ISO standard 14342-1 was compared with American Society for Testing and Materials (ASTM) F3141. They found a very similar overall wear rate (13.64-54.9 $\mathrm{mm}^{3} /$ million vs. $13.48-55.26 \mathrm{~mm}^{3} /$ million) but different wear contours and wear depth [7].

These differences in wear may result in problems for medical companies. For example, for the approval of a new medical device, the new European Medical Device Regulation (MDR) or American Food and Drug Administration (FDA) provides the possibility of using clinical data related to an equivalent device, sometimes called a "predicate device", in the clinical evaluation process. For the MDR, this is only possible if the technical, biological, and clinical characteristics are equivalent; therefore, full access to the technical documentation of the medical device is needed, which will lead in many cases to a situation where results may only be compared within inhouse products. However, if the differences in the load and motion profiles across different ISO standard versions are too great, and knowing that these kinematic profiles and loads strongly influence the generation of wear, comparisons will be difficult [8]. This leads to problems in the certification process of new implants, because if experimental wear tests are no longer comparable due to major changes over the years, companies lose the possibility of comparing results to their old result database.

The aim of this study was therefore to compare the different ISO standards across different publication years and loading concepts and to gain a deeper insight into the resulting kinematics and differences in stress in the polyethylene insert. To discover whether low congruence inlay designs are more affected by different loading conditions, the differences in inlay design across the standards should be analysed.

We hypothesise that (1) each norm will result in different inlay stresses (three norms tested: ISO 14243-1:2002, ISO 14243-1:2009, and ISO 14243-3:2014) within the same inlay design, and (2) the force-controlled norm will differ in stress and kinematics between 2002 and 2009. The comparison of the kinematics and the stress behaviour is investigated using finite element methods.

\section{Materials and Methods}

\subsection{General}

Nine different finite element models were constructed for the different inlay designs of one prosthesis (Aesculap, Tuttlingen, Germany) and the different ISO standards tested in this study (Table 1). A validation between the experimental wear tests and the in silico model was established. Therefore, the boundary conditions of ISO 14243-1:2002 (forcecontrolled) and the deep dish inlay design were used. Based on this validated computer model, different modifications corresponding to the different ISO standards or inlay designs were established. In this study, three different inlay designs were used: cruciate-retaining $(\mathrm{CR})$, deep dish (DD), and ultra-congruent (UC). All inlays were compatible with the Columbus ${ }^{\circledR}$ knee system (Aesculap, Tuttlingen, Germany). 
Table 1. Overview of the different model conditions for ISO norms 14243-1:2002 force-controlled (FC), 14243-1:2009 FC (without posterior cruciate ligament (PCL) and with PCL), and 14243-3:2014 displacement-controlled (DC).

\begin{tabular}{|c|c|c|c|c|}
\hline \multirow{2}{*}{$\begin{array}{c}\text { Inlay Design } \\
-\end{array}$} & \multirow{2}{*}{$\begin{array}{c}\text { ISO Norm 14243-1:2002 (FC) } \\
-\end{array}$} & \multicolumn{2}{|c|}{ ISO Norm 14243-1:2009 (FC) } & \multirow{2}{*}{$\begin{array}{c}\text { ISO Norm 14243-3:2014 (DC) } \\
-\end{array}$} \\
\hline & & Without PCL & With PCL & \\
\hline $\begin{array}{l}\text { Cruciate-Retaining } \\
\text { (CR) }\end{array}$ & $\begin{array}{l}\text { anterior/posterior spring: } 30 \mathrm{~N} / \mathrm{mm} \\
\text { torsional spring: } 600 \mathrm{Nmm} /{ }^{\circ}\end{array}$ & - & $\begin{array}{l}\text { anterior spring: } 44 \mathrm{~N} / \mathrm{mm} \\
\text { posterior spring: } 9.3 \mathrm{~N} / \mathrm{mm} \\
\text { torsional spring: } 360 \mathrm{Nmm} /{ }^{\circ} \\
\text { Note: First } \pm 2.5 \mathrm{~mm}(\mathrm{a} / \mathrm{p} \\
\text { spring) and } \pm 6^{\circ} \text { (torsional } \\
\text { spring) without constraint }\end{array}$ & $\begin{array}{l}\text { No spring-defined via } \\
\text { displacement control }\end{array}$ \\
\hline Deep Dish (DD) & $\begin{array}{l}\text { anterior/posterior } \\
\text { spring: } 30 \mathrm{~N} / \mathrm{mm} \\
\text { torsional spring: } \\
\quad 600 \mathrm{Nmm} /{ }^{\circ}\end{array}$ & - & $\begin{array}{l}\text { anterior spring: } 44 \mathrm{~N} / \mathrm{mm} \\
\text { posterior spring: } 9.3 \mathrm{~N} / \mathrm{mm} \\
\text { torsional spring: } 360 \mathrm{Nmm} /{ }^{\circ} \\
\text { Note: First } \pm 2.5 \mathrm{~mm}(\mathrm{a} / \mathrm{p} \\
\text { spring) and } \pm 6^{\circ} \text { (torsional } \\
\text { spring) without constraint }\end{array}$ & $\begin{array}{l}\text { No spring-defined via } \\
\text { displacement control }\end{array}$ \\
\hline Ultra-Congruent (UC) & $\begin{array}{l}\text { anterior/posterior } \\
\text { spring: } 30 \mathrm{~N} / \mathrm{mm} \\
\text { torsional spring: } \\
600 \mathrm{Nmm} /{ }^{\circ}\end{array}$ & $\begin{array}{l}\text { anterior spring: } 9.3 \mathrm{~N} / \mathrm{mm} \\
\text { posterior spring: } 9.3 \mathrm{~N} / \mathrm{mm} \\
\text { torsional spring: } 360 \mathrm{Nmm} /{ }^{\circ} \\
\text { Note: First } \pm 2.5 \mathrm{~mm}(\mathrm{a} / \mathrm{p} \\
\text { spring) and } \pm 6^{\circ} \text { (torsional } \\
\text { spring) without constraint }\end{array}$ & - & $\begin{array}{l}\text { No spring-defined via } \\
\text { displacement control }\end{array}$ \\
\hline
\end{tabular}

\subsection{Experimental Setup of the Wear Simulator for Validation of the Finite Element Model}

An experimental wear simulator test to validate the in silico model was performed on a servo-hydraulic knee wear simulator (EndoLab GmbH, Rohrdorf, Germany). The kinematic and force patterns for the mechanical simulator were based on level walking according to ISO standard 14243-1:2002 (force-controlled standard) [9]. Internal/external rotational torque, anterior/posterior force, and axial force were generated by hydraulic cylinders accordingly. The axial force was applied in a medio-lateral compartment ratio of $60 \%$ to $40 \%$; therefore, a lateral implantation offset of $5.6 \mathrm{~mm}(0.07$ times the width of the tibial component) was implemented. To simulate the knee ligaments, the wear simulator included spring restraints of $30 \mathrm{~N} / \mathrm{mm}$ in anterior/posterior translation and $600 \mathrm{Nmm} /{ }^{\circ}$ in internal/external rotation, also defined in the ISO standard.

The movement constraints of the various components of the knee system in the wear simulator were as follows: The femoral component was restricted to move in anterior/posterior, medial/lateral, axial translation, internal/external rotation, and varus/valgus rotation. Flexion/extension was free, and the axis of the J-curved femoral component was developed according to the ISO standard. In two positions, $30^{\circ}$ of flexion and $60^{\circ}$ of flexion viewed on the sagittal plane, a line was drawn perpendicular to the ground and through the contact point of the femoral condyles. The crossover point of these two lines was defined as the flexion/extension axis. The tibial component was only restricted in flexional rotation. Anterior/posterior, medial/lateral, and axial movement were free, while varus/valgus and internal/external rotation were possible. For comparison with the in silico model, the kinematic data of the experimental setup were processed after 5000 cycles to ensure that the same surface geometry was maintained between the in silico model (no wear simulated) and the experiment due to the changing surface during the experimental wear test.

\subsection{Computational Model}

\section{Kinematic Validation and Basic Model for ISO 14243-1:2002 (Force-Controlled)}

The validation computer model was based on the ISO standard 14243-1:2002 (forcecontrolled standard), and for the equal inlay design which was used in the experimental setup, a deep dish (DD) design was used. The CAD file was imported into Ansys Workbench software (V16; Ansys, Inc., Canonsburg, PA, USA). The femoral component, inlay, and tibial baseplate were positioned in a neutral starting position to conform with the ISO standard [9]. The tibial base plate was embedded in a round rigid body according to the ISO standard with a lateralisation of $7 \%$ of the width, equivalent to that in the experimental 
tests. Flexion/extension was free, and the axis of the J-curved femoral component was developed according to the experimental setup.

The boundary conditions of the tibial baseplate were established on the bottom of the rigid body representing the embedded tibial component in resin (Figure 1). For translational movement, it was free to move in the medial/lateral, anterior/posterior, and proximal/distal (axial) directions. For rotational movement, it was free to rotate internally/externally and was free in varus/valgus rotation. Rotation around the $x$-axis, which represented the slope axis, was restricted during the whole simulation according to the ISO standard and the experimental setup.

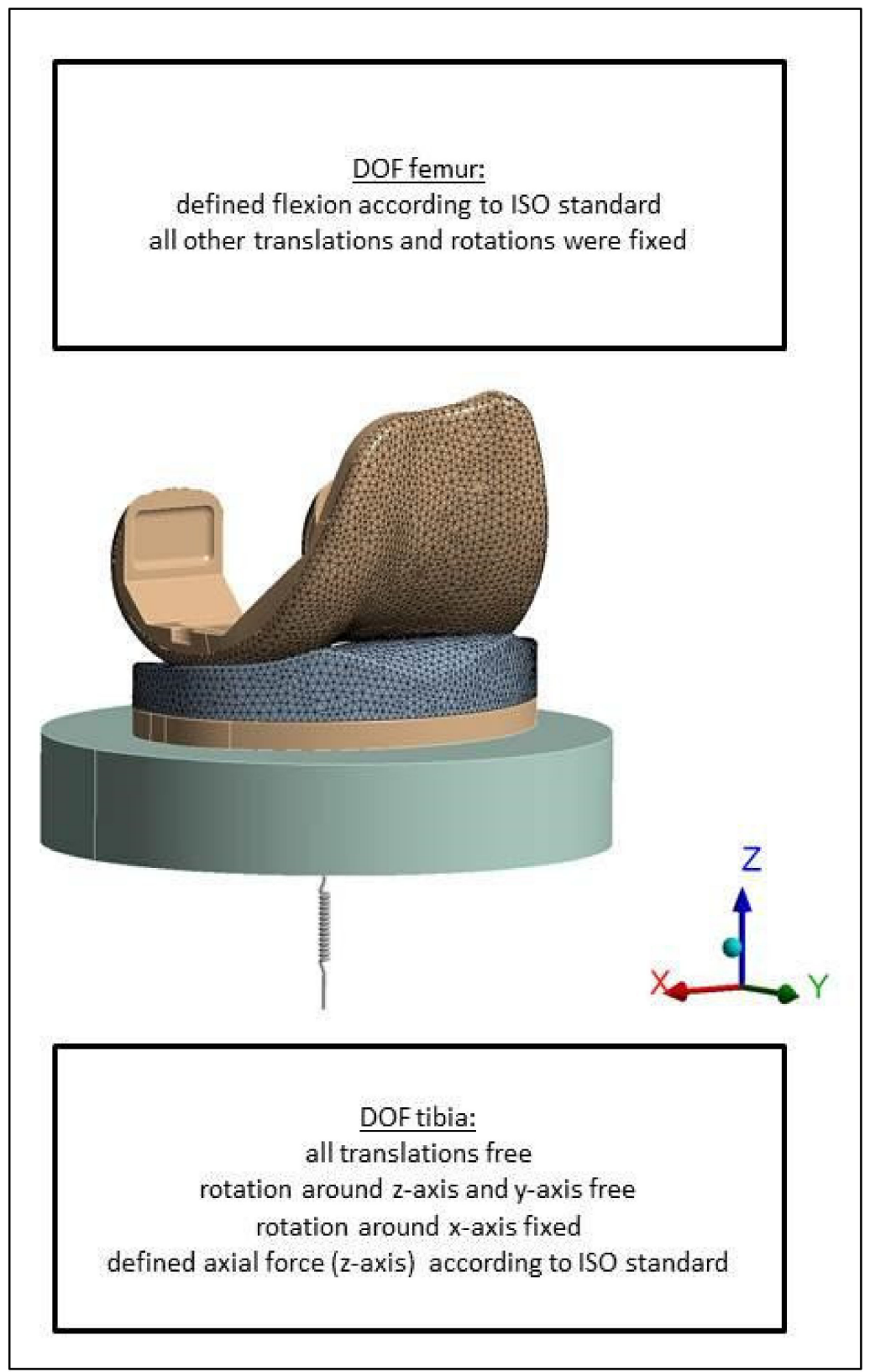

Figure 1. Structure of the finite element (FE) model with the degrees of freedom (DOF) for femur and tibia according to the International Organization for Standardization (ISO).

Forces for anterior/posterior translation, internal/external rotation (torque), and axial force were also established on the resin body. The anterior/posterior force was applied to the posterior part, while the axial force and the rotational torque were applied to the bottom part of the resin body. Due to the $7 \%$ lateral translation of the tibia and inlay 
component during implantation, the line of action of the forces was secured according to the ISO standard.

Restraint system-simulating ligaments and a capsule environment were added to the simulation with a linear spring according to the ISO standard with $30 \mathrm{~N} / \mathrm{mm}$ in the anterior/posterior direction with a linear spring element. A restraint system for internal/external rotation of the tibia was also implemented via a linear spring element, i.e., a torsional spring element with $600 \mathrm{Nmm} /{ }^{\circ}$.

Femorotibial contact was established in the finite element model using an augmented Lagrange algorithm and a basic frictional coefficient of 0.05 [10,11]. To confirm the frictional coefficient, variations of $0.01,0.03$, and 0.08 were calculated and compared with the experimental kinematic data. The contacts between the inlay, tibial base plate, and the rigid body representing the embedded resin were defined as fixed joints in the simulation, which means no separation was possible, and all bodies except the inlay were not deformable. One hundred and four load steps were implemented in the in silico model to simulate the gait cycle. The first four loading steps were used to establish the initial contact between the femoral component and the inlay of the prosthesis, which is necessary in a computer model. The remaining 100 loading steps were the gait cycle steps, which are specified by the ISO standard.

\subsection{Numerical Model Validation}

The model validation was performed with the DD inlay using the described experimental wear simulator. For kinematic comparison, the Pearson correlation coefficient (r) was used and secured with different frictional coefficients within the simulation. For finite element models, it is necessary to conduct a mesh validation, which is known as a convergence study. Since the TKA design was also used in an earlier validated study, the mesh size was identical to that used in a validation study by Woiczinski et al. [12]. The correlation for the kinematic comparision was calculated by using the following formula (1):

$$
r=\frac{\sum_{i=1}^{n}\left(x_{i}-\bar{x}\right) *\left(y_{i}-\bar{y}\right)}{\sqrt{\sum_{i=1}^{n}\left(x_{i}-\bar{x}\right)^{2} * \sum_{i=1}^{n}\left(y_{i}-\bar{y}\right)^{2}}}
$$

\subsection{Model Variation 1: New ISO 14243-1:2009 (Force-Controlled)}

The newer ISO standard was adapted and compared to the version from the year 2002. In the new standard, some boundary conditions differ between the different inlay designs. For example, there is a difference in the restraint system for cruciate-retaining inlays compared to that for ultra-high-congruence inlays. To represent these changing boundary conditions, the initial numerical model (ISO 14243:2002) was adapted accordingly to meet the newer standard [13]. For the CR computer model, the spring elements were changed to tension-only elements. In the resin body, an anterior-positioned spring, which restrains posterior movement of the tibia, was added with a spring rate of $44 \mathrm{~N} / \mathrm{mm}$, simulating a posterior cruciate ligament according to the ISO standard. In contrast, in the resin body, a posterior-positioned spring with a rate of $9.3 \mathrm{~N} / \mathrm{mm}$ was added to restrain anterior movement of the tibia, simulating only the capsule of the knee, because no anterior cruciate ligament is currently present in this type of prosthesis design. Furthermore, both spring elements had no restraint in $\pm 2.5 \mathrm{~mm}$ anterior/posterior movement from a neutral position, also according to the ISO standard. The torsional spring was adapted to the new standard with a restraint force of $360 \mathrm{Nmm} /{ }^{\circ}$ and no restraint up to $\pm 6^{\circ}$ starting at a neutral position. The boundary conditions and forces within the norm were equal to those in the old ISO standard and therefore were not changed in this in silico model.

\subsection{ISO 14243-3:2014 Model (Displacement-Controlled)}

In contrast to the force-controlled standard, there is no anterior/posterior force or internal/external torque defined in ISO 14243-3:2014. The movements in these directions are displacement-controlled. These boundary conditions were changed in the computer 
model according to the ISO standard [14]. Furthermore, no restraint system is required due to the displacement-controlled movement, which is why the spring elements were removed in the in silico model. The axial force and flexion profile were not changed in the model because they are equal to those in the force-constrained ISO standard.

\section{Results}

\subsection{Validation}

All different friction models showed a good comparison with the experimental movement tests (Figure 2). The correlation coefficients for the anterior/posterior movement ranged from $r=0.91$ for the model with a frictional coefficient of 0.01 and $r=0.87$ for a frictional coefficient of 0.08 . For the rotational data, also, all in silico models presented a good trend compared to the experimental data. The correlation coefficients ranged from $\mathrm{r}=0.80$ for a 0.01 friction coefficient and $\mathrm{r}=0.81$ for a 0.08 friction coefficient.

\section{a.}

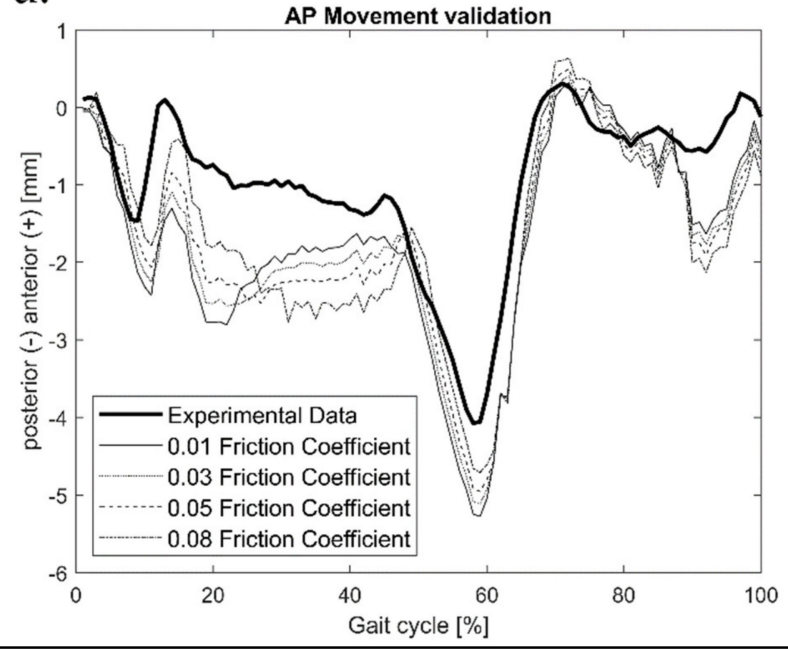

b.

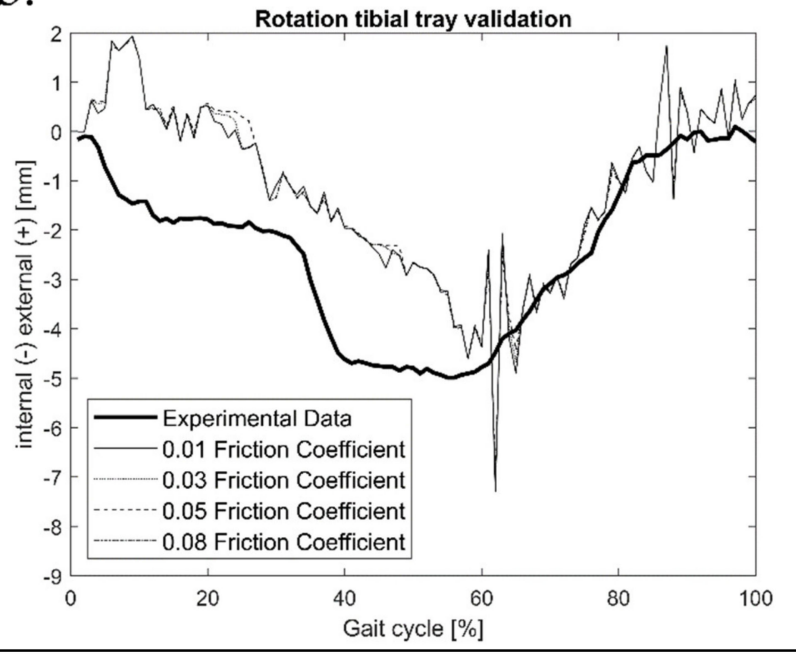

Figure 2. Validation with the deep dish (DD) inlay with different friction coefficients; (a) anterior/posterior (AP) movement, (b) tibia rotation.

\subsection{Comparison of FC-2002, FC-2009, and DC-2014 with the CR Inlay}

The results of this comparison are presented in Figure 3. Stress in the CR inlay during the gait cycle showed two peaks of $12.38 \mathrm{MPa}$ and 9.27 MPa for FC-2002 and another two of 20.59 MPa and 17.19 MPa for the DC-2014 standard. FC-2009 generated three maxima of $11.15 \mathrm{MPa}, 10.15 \mathrm{MPa}$, and 9.16 MPa. These results are also shown in Figure 4. For the anterior/posterior translation of the tibia, one maximum was seen at $57 \%$ of the gait cycle in the posterior direction $(4.74 \mathrm{~mm})$ for FC-2002, and a second maximum was observed at $71 \%$ of the gait cycle for FC-2009 in the anterior direction $(7.51 \mathrm{~mm})$. DC-2014 generated an anterior/posterior movement profile of two maxima in the anterior direction, as predefined at $18 \%$ and $57 \%$ of the gait cycle, with values of $4.47 \mathrm{~mm}$ and $5.13 \mathrm{~mm}$, respectively. Rotational data showed an internally rotating tibia for FC-2002, with a maximum of $6.18^{\circ}$ at $54 \%$ of the gait cycle, and for FC-2009, with a maximum of $9.00^{\circ}$ at $56 \%$ of the gait cycle. DC-2014 generated, as predefined, one maximum at the end of the gait cycle of $90 \%$ in the $5.72^{\circ}$ external direction. 




Figure 3. Results of stress and kinematic analysis for different ISO norms (14243-1:2002, 14243-1:2009, 14243-3:2014) and inlays (cruciate-retaining—CR, deep dish—DD, ultra-congruent—UC). 
a.
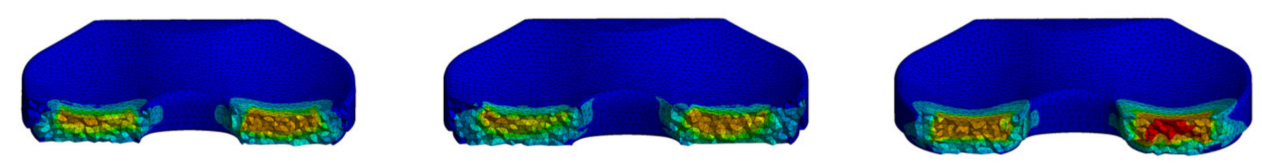

14243:2002 FC

14243:2009 FC

14243:2014 DC

b.
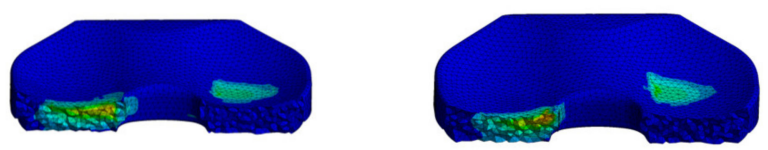

14243:2002 FC

14243:2009 FC

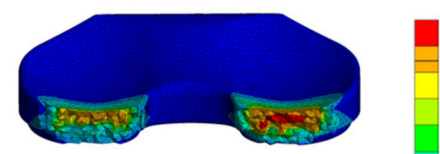

$17 \mathrm{MPa}$

5

14243:2014 DC

C.
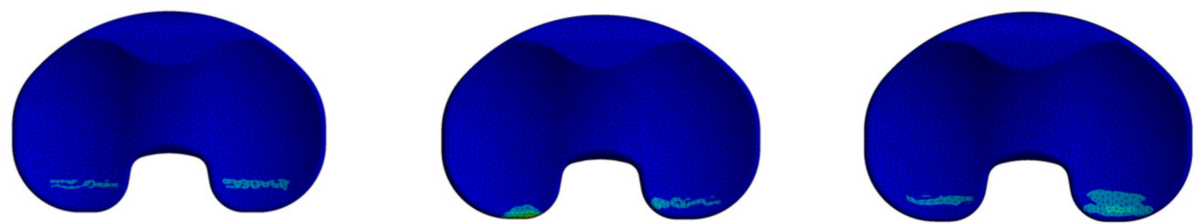

14243:2002 FC

14243:2009 FC

14243:2014 DC

Figure 4. Stress in the cruciate-retaining (CR) inlay for different ISO norms: (a) first peak, (b) second peak, (c) third peak.

\subsection{Comparison of Different Inlay Designs}

In addition to the main questions, a comparison of different inlays within one standard was carried out. Within FC-2002, the different design variants generated different stresses and different anterior/posterior and rotational movement. The maximum stresses in the CR, DD, and UC inlays were lower in FC-2002 and FC-2009 and higher in DC-2014. Furthermore, FC-2009 generated no third peak value within the UC inlay in the swing phase, unlike the other designs (CR and DD). Kinematic data showed different values for FC-2002 and the CR inlay variant compared to the DD and UC designs. To be more precise, between $20 \%$ and $50 \%$ of the gait cycle, the CR inlay moved less in the posterior direction in FC-2002 than did the other designs. Anterior/posterior movement was similar in FC-2002 for the DD and UC inlays. In FC-2009, more anterior movement was observed with a maximum of $7.51 \mathrm{~mm}$ at $72 \%$ of the gait cycle with the CR inlay. The DD and UC inlays showed less anterior movement at the same percentage of the gait cycle. The UC inlay showed greater posterior movement of $9.69 \mathrm{~mm}$ at $60 \%$ of the gait cycle in FC-2009. Rotational data showed no difference between the inlay designs for FC-2002 and DC-2014. More internal rotation was seen for the CR inlay in FC-2009 compared to the DD and UC inlays.

\section{Discussion}

The main important finding of this study is that the force-controlled norms of 2002 and 2009 are different in the resulting femorotibial kinematics and von Mises stress behaviour within the inlay over the gait cycle. Moreover, the displacement-controlled standard from 2014 generated up to four times more von Mises stress in all three tested inlay designs. 
There were differences between FC-2002 and FC-2009 regarding the kinematic results within the CR inlay. FC-2009 led to more internal rotation in all inlays than FC-2002. Furthermore, at about $75 \%$ of the gait cycle, increased anterior movement was observed with the FC-2009 norm compared to FC-2002. The ISO standard changed from 2002 to 2009 by modifying the anterior/posterior and torsional springs ( 30 to $44 \mathrm{~N} / \mathrm{mm}$ and 600 to $360 \mathrm{Nmm} /{ }^{\circ}$ ) and adding a slack condition for $\pm 2.5 \mathrm{~mm}$ (a/p spring) and $\pm 6^{\circ}$ (torsional spring). As a result, the movement experiences less resistance. This might explain the increased anterior movement and internal rotation of the tibia in the model with the ISO 2009 standard for all inlays. The adapted force-controlled ISO from 2009 showed higher mechanical stress during the gait cycle in the $\mathrm{CR}$ and DD designs, which might also lead to higher wear rates. In general, the changes in the standard from 2002 to 2009 show an increase in the range of motion. This can have a negative effect on the wear contact area of both components in the form of increased wear. Studies by Grupp et al. and Kretzer et al. were also able to confirm this observation with an increased amount of abrasion particles found across different ISO norms $[8,15,16]$. Grupp et al. compared the kinematics of posterior-stabilised inlays produced according to the standard protocol ISO 14243-1 versions from 2002 and 2009. In agreement with our results, they found a change in anterior/posterior (AP) translation and internal/external rotation, which resulted in a 3.2 times higher wear rate. They came to the conclusion that a change in the kinematics has a strong influence on the wear behaviour in TKA [16].

Compared to FC-2009, the displacement-controlled ISO standard (2014) can lead to a higher mechanical load due to displacement-controlled movement. In the FC-2009 norm, an additional peak at about $70 \%$ of the gait cycle occurred for CR and DD designs compared to the older version. The maximum contact pressure occurred as expected with each inlay on the medial side. However, DC-2014 showed a more dorsal distribution of the pressure, resulting in a smaller surface. This can be explained by the fact that displacement control dictates anterior movement of the inlay, whereas force control is directed both anteriorly and posteriorly. The DC-2014 standard is controlled by a defined path. This control mechanism does not account for possible resistance in the joint. Therefore, the standard automatically leads to more movement in the prosthetic joint and creates more von Mises stress. Increased stress in the inlay can also lead to increased wear of the prosthesis. This fact leads to the problem that if the prostheses are tested with different standards, higher wear cannot automatically be attributed to the type of prosthesis. The different results of the tested standards are extremely limited in terms of comparability.

In a comparison of different inlay designs, increased movement in the posterior direction with a maximum at the beginning of the swing phase was only seen in the UC inlay for FC-2009. The more paradoxical posterior displacement of the UC inlay can be explained by the different definition of the restraint spring system $(9.3 \mathrm{~N} / \mathrm{mm}$ vs. $44 \mathrm{~N} / \mathrm{mm}$ ). The maximum total rotation increased from $7.0^{\circ}$ to $10.1^{\circ}$ for the UC inlay. A similar increase from $5.2^{\circ}$ to $12.0^{\circ}$ was also determined by Grupp et al., who investigated the renewal of the norm using a posterior stabilised inlay [16]. Kretzer et al. found an increase from $4.1^{\circ}$ to $7.7^{\circ}$, where only the change in the nonlinear spring constraint was congruent with this experiment, since the level of resistance of the springs remained the same [8]. Regarding the stress in the DC norm, the DD and UC inlays for the displacementcontrolled standard had the highest values. The DC norm forces the inlay to a specified position, so that the strong curvature of the inlay acts as a resistance to the femur and thus leads to an increased pressure load on the inlay surface. Barnett et al., Knight et al., and McEwen et al. also came to the conclusion in previous work that different kinematic conditions specified by different ISO standards lead to changes in wear [17-19]. Wear was demonstrably decreased when AP movements and internal/external rotation were reduced. Zietz et al. confirmed as much [20]. Even the definition of the ISO standard states that "(..) this part of ISO 14243 may not be applicable to knee designs with a high degree of constraints (..)" [14]. This statement can be interpreted as a warning that inlays like UC and possibly DD should not be tested with this standard; however, it does not prohibit it. 
This explains the extremely high values and deviations in standards for the UC and DD inlays compared to the CR inlay.

The created finite element model (FEM) was first validated using existing experimental data for the DD inlay. A mean value of 0.05 for the coefficient of friction seemed appropriate for further calculations. Godest et al. used a similar approach in their work and achieved comparable results [21].

Of course, our study has some limitations. One is that the calculations are based on a computer model. A model can only ever give an approximation of the actual results in humans. Furthermore, it must be noted that this is not an in vivo study. Moreover, a computer model always brings a certain amount of error into the calculations. Components that are not represented within the simulation compared to the experiment may influence results. Therefore, a validation process is mandatory for each in silico computer model to ensure slight and unrecognised different loadings. Another limitation is that our computer model did not measure the wear, so due to the changed kinematics and contact stress only a tendency can be expressed.

\section{Conclusions}

In conclusion, it can be stated that all ISO standards induced different stresses, AP movement, and tibia rotation in all inlay designs. The adapted force-controlled ISO from the year 2009 showed higher mechanical stress and AP motion during the gait cycle because of the different spring system. The displacement-controlled ISO led to higher mechanical stress. If the results of the present study are considered in light of the new MDR, it becomes clear that not only must the same standard (force-controlled vs. displacementcontrolled) basis be used for testing new products, but the same version must also be used (2002 vs. 2009 vs. 2014). If older, already-approved medical devices are tested using an older ISO standard version, the results of kinematics and pressure behaviour are not comparable. Thus, approval of a medical product by the MDR should only be given if the test requirements are the same. Future studies should analyse different inlay designs within the same ISO standards to guarantee comparability.

Author Contributions: Conceptualisation, C.S., M.W., and L.B.; methodology, M.K., K.I.; data citation, L.B.; validation, K.I., C.S. and M.W.; formal analysis, L.B.; writing—original draft preparation, L.B., A.S. and M.W.; writing—review and editing, P.E.M., V.J.; visualisation, L.B., M.W.; supervision, M.W.; project administration, M.W., P.E.M. and V.J. All authors have read and agreed to the published version of the manuscript.

Funding: This research received no external funding.

Institutional Review Board Statement: Not applicable.

Informed Consent Statement: Not applicable.

Data Availability Statement: The data cannot be made available for company law reasons.

Acknowledgments: The authors wish to thank Aesculap for providing the prosthesis system.

Conflicts of Interest: The authors declare no conflict of interest.

\section{References}

1. Grimberg, A.; Volkmar, J.; Melsheimer, O. Jahresbericht 2019; EPRD Deutsche Endoprothesenregister: Berlin, Germany, 2019.

2. Kurtz, S.; Ong, K.; Lau, E.; Mowat, F.; Halpern, M. Projections of primary and revision hip and knee arthroplasty in the United States from 2005 to 2030. J. Bone Jt. Surg. Am. 2007, 89, 780-785. [CrossRef]

3. Schwenke, T.; Orozco, D.; Schneider, E.; Wimmer, M. Differences in wear between load and displacement control tested total knee replacements. Wear 2009, 267, 757-762. [CrossRef]

4. Brockett, C.L.; Abdelgaied, A.; Haythornthwaite, T.; Hardaker, C.; Fisher, J.; Jennings, L.M. The influence of simulator input conditions on the wear of total knee replacements: An experimental and computational study. Proc. Inst. Mech. Eng. Part H J. Eng. Med. 2016, 230, 429-439. [CrossRef] [PubMed]

5. Sutton, L.G.; Werner, F.W.; Haider, H.; Hamblin, T.; Clabeaux, J.J. In vitro response of the natural cadaver knee to the loading profiles specified in a standard for knee implant wear testing. J. Biomech. 2010, 43, 2203-2207. [CrossRef] [PubMed] 
6. Mell, S.P.; Fullam, S.; Wimmer, M.A.; Lundberg, H.J. Finite element evaluation of the newest ISO testing standard for polyethylene total knee replacement liners. Proc. Inst. Mech. Eng. Part H J. Eng. Med. 2018, 23, 545-552. [CrossRef] [PubMed]

7. Wang, X.-H.; Li, H.; Dong, X.; Zhao, F.; Cheng, C.-K. Comparison of ISO 14243-1 to ASTM F3141 in terms of wearing of knee prostheses. Clin. Biomech. 2019, 63, 34-40. [CrossRef] [PubMed]

8. Kretzer, J.P.; Jakubowitz, E.; Sonntag, R.; Hofmann, K.; Heisel, C.; Thomsen, M. Effect of joint laxity on polyethylene wear in total knee replacement. J. Biomech. 2010, 43, 1092-1096. [CrossRef] [PubMed]

9. International Organization for Standardization. International Standard, Implants for Surgery—Wear of Total Knee-Joint ProsthesesPart 1: Loading and Displacement Parameters for Wear-Testing Machines with Load Control and Corresponding Environmental Conditions for Test; ISO: Geneva, Switzerland, 2002.

10. Gispert, M.; Serro, A.; Colaco, R.; Saramago, B. Friction and wear mechanisms in hip prosthesis: Comparison of joint materials behaviour in several lubricants. Wear 2006, 260, 149-158. [CrossRef]

11. Kyomoto, M.; Iwasaki, Y.; Moro, T.; Konno, T.; Miyaji, F.; Kawaguchi, H.; Takatori, Y.; Nakamura, K.; Ishihara, K. High lubricious surface of cobalt-chromium-molybdenum alloy prepared by grafting poly (2-methacryloyloxyethyl phosphorylcholine). Biomaterials 2007, 28, 3121-3130. [CrossRef] [PubMed]

12. Woiczinski, M.; Steinbrück, A.; Weber, P.; Müller, P.E.; Jansson, V.; Schröder, C. Development and validation of a weight-bearing finite element model for total knee replacement. Comput. Methods Biomech. Biomed. Engin. 2016, 19, 1033-1045. [CrossRef] [PubMed]

13. International Organization for Standardization. International Standard, Implants for Surgery—Wear of Total Knee-Joint ProsthesesPart 1: Loading and Displacement Parameters for Wear-Testing Machines with Displacement Control and Corresponding Environmental Conditions for Test; ISO: Geneva, Switzerland, 2009.

14. International Organization for Standardization. International Standard, Implants for Surgery—Wear of Total Knee-Joint ProsthesesPart 3: Loading and Displacement Parameters for Wear-Testing Machines with Displacement Control and Corresponding Environmental Conditions for Test; ISO: Geneva, Switzerland, 2014.

15. Grupp, T.M.; Saleh, K.J.; Mihalko, W.M.; Hintner, M.; Fritz, B.; Schilling, C.; Schwiesau, J.; Kaddick, C. Effect of anterior-posterior and internal-external motion restraint during knee wear simulation on a posterior stabilised knee design. J. Biomech. 2013, 46, 491-497. [CrossRef] [PubMed]

16. Grupp, T.M.; Schroeder, C.; Kim, T.K.; Miehlke, R.K.; Fritz, B.; Jansson, V.; Utzschneider, S. Biotribology of a mobile bearing posterior stabilised knee design-effect of motion restraint on wear, tibio-femoral kinematics and particles. J. Biomech. 2014, 47, 2415-2423. [CrossRef] [PubMed]

17. Barnett, P.I.; Fisher, J.; Auger, D.D.; Stone, M.H.; Ingham, E. Comparison of wear in a total knee replacement under different kinematic conditions. J. Mater. Sci. Mater. Med. 2001, 12, 1039-1042. [CrossRef] [PubMed]

18. Knight, L.A.; McEwen, H.M.; Farrar, R.; Stone, M.H.; Fisher, J.; Taylor, M. The Influence of the Wear Path on the Wear Rates in Total Knee Replacement. In Proceedings of the 2003 Summer Bioengineering Conference, Key Biscayne, FL, USA, 25-29 June 2003

19. McEwen, H.M.; Barnett, P.I.; Bell, C.J.; Farrar, R.; Auger, D.D.; Stone, M.H.; Fisher, J. The influence of design, materials and kinematics on the in vitro wear of total knee replacements. J. Biomech. 2005, 38, 357-365. [CrossRef]

20. Zietz, C.; Reinders, J.; Schwiesau, J.; Paulus, A.; Kretzer, J.; Grupp, T.; Utzschneider, S.; Bader, R. Experimental testing of total knee replacements with UHMW-PE inserts: Impact of severe wear test conditions. J. Mater. Sci. Mater. Med. 2015, 26, 1-13. [CrossRef] [PubMed]

21. Godest, A.C.; Beaugonin, M.; Haug, E.; Taylor, M.; Gregson, P.J. Simulation of a knee joint replacement during a gait cycle using explicit finite element analysis. J. Biomech. 2002, 35, 267-275. [CrossRef] 